\title{
JSC Mars-1 Martian Soil Simulant: Melting Experiments and Electron Microprobe Studies
}

\author{
P. Carpenter*, L. Sebille*, W. Boles**, M. Chadwell***, and L. Schwarz**** \\ * SD46 / USRA / NASA, Marshall Space Flight Center, AL 35812 \\ ** Dept. of Eng. Tech. and Industrial Studies, Middle Tennessee State University, Murfreesburo, \\ $\mathrm{TN}$ \\ *** Dept. of Earth Sciences, University of South Alabama, Mobile, AL \\ **** Dept. of Civil and Environmental Engineering, University of Alabama, Huntsville, AL
}

JSC Mars-1 has been developed as a Martian regolith simulant, and is the $<1 \mathrm{~mm}$ size fraction of a palagonitic tephra (a glassy volcanic ash altered at low temperatures) from Pu'u Nene cinder cone on the Island of Hawaii [1]. The Mars-1 simulant forms the basis for numerous terrestrial studies which aim to evaluate the suitability of Martian soil for materials processing. Martian soil may be sintered to form building materials for construction, and also melted or reacted to extract metals for various uses, as well as oxygen for life support.

Mars-1 material was dry sieved to evaluate mineralogical abundances that are specific to a size fraction. Representative samples of these fractions were mounted and polished for electron microprobe analysis, and also ground for x-ray diffraction analysis. The coarser fractions are comprised of lithic fragments, glassy material, and amorphous palagonite weathering products. The lithic fragments contain plagioclase, olivine, titanomagnetite, pyroxene, and basaltic glass. EPMA and $\mathrm{x}$-ray diffraction analysis suggest that in situ weathering of basaltic glass forms the palagonite (figures 1 and 2), and that the palagonite and other amorphous material persists from coarse grain size $(\sim 1 \mathrm{~mm})$ down to the smallest size sampled $(<50 \mu \mathrm{m})$.

Melting experiments were performed in a 1 atm furnace using crucibles composed of alumina or boron nitride and a continuous argon purge. Samples were heated above the liquidus temperature to completely melt the ash material. Invasion of porous alumina crucibles was observed with extensive reaction of melt with alumina to precipitate spinel-family minerals. Low porosity alumina crucibles gave better results, and boron nitride crucibles produced minimal wetting. Experiments performed in boron nitride crucibles yielded FeP composite grains that settled or nucleated at the base of the melt body, and dispersed metallic iron particles within the melt body (figures 3 and 4). Melt experiments were also performed using a microwave oven and alumina crucibles. JSC-1 material was combined with powdered graphite and samples subsequently melted. These experiments yielded composite FeP grains and dispersed metallic iron particles as well. Temperature gradients were presumably quite steep as completely melted glass is observed in the crucible interior with extensive plagioclase crystallization at the crucible wall. From these experiments it is apparent that breakdown of olivine releases iron into the melt during melting, and that phosphorous is intimately involved in the precipitation of FeP composite grains during cooling. Other nominally trace elements may be scavenged into the FeP grains. Production of high purity iron is complicated by these factors.

JSC Mars-1 simulant was selected due to close similarity of optical spectra to the bright regions of Mars. The chemical composition of Mars- 1 is similar to existing Martian soil analyses from the Viking lander and Pathfinder missions for $\mathrm{SiO}_{2}, \mathrm{Fe}_{2} \mathrm{O}_{3}$, and $\mathrm{CaO}$, but differs significantly for $\mathrm{Al}_{2} \mathrm{O}_{3}$, $\mathrm{TiO}_{2}, \mathrm{MgO}$ [2]. The Martian soil has a much lower water content, but conversely has a high sulfur content, compare to Mars-1. These differences are important for materials processing and element extraction studies, and it will be important to develop a simulant that is more chemically similar to the Martian soil for these studies. 


\section{References}

[1] C.C. Allen et al., Proceedings of Lunar and Planetary Science $29^{\text {th }}, 1998$.

[2] C.C. Allen et al., EOS Transactions, AGU, 79 (34), 1998.
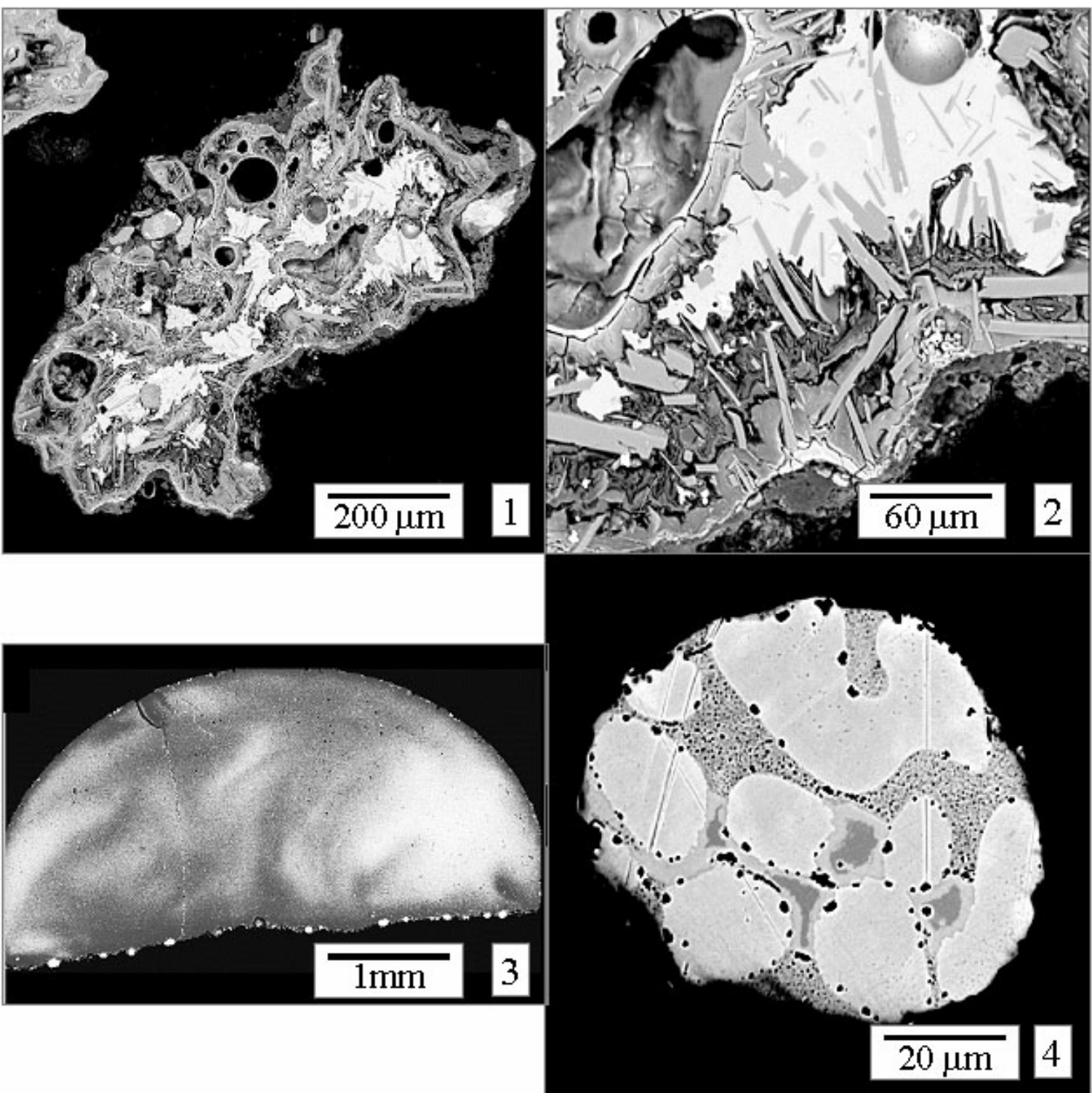

Figure 1. Lithic grain of JSC Mars-1. Backscattered electron image illustrating basalt glass (bright), plagioclase laths (gray), and amorphous palagonite (variable dark gray) lining vesicles and rimming grain. Figure 2. Magnified portion of grain in figure 1. Basalt glass weathers to palagonite, leaving plagioclase laths intact.

Figure 3. Quenched basalt glass bead from melting experiment (argon, BN crucible). Backscattered electron image illustrating contrast due to Fe concentration and settled or nucleated $\mathrm{FeP}$ spherules.

Figure 4. Magnified portion of FeP composite grain in figure 3. Decreasing backscattered electron brightness represents increasing $\mathrm{P}$ content of FeP phases. Note segregation of P-rich phases toward the base of the composite grain. 